\title{
Práticas Pedagógicas em Matemática: experiências em uma escola do Programa UCA
}

\author{
Denice Aparecida Fontana Nisxota Menegais, PGIE/ UFRGS, denice.menegais@gmail.com \\ Cristina Maria Pescador, PGIE/ UFRGS, cpescador@gmail.com \\ Léa da Cruz Fagundes, PGIE/ UFRGS, leafagun@ufrgs.br
}

\begin{abstract}
Resumo: O presente artigo tem como objetivo analisar as práticas pedagógicas dos professores de matemática por meio de projetos de aprendizagem desenvolvidos em uma escola de educação básica da rede pública, localizada na cidade de Panambi, Estado do Rio Grande do Sul, quando da implantação do Programa UCA e distribuição de laptops educacionais na modalidade 1:1. Como abordagem metodológica, para a realização desta pesquisa, realizou-se uma entrevista com a diretora da escola e a aplicação de um questionário aos professores de matemática. O estudo apontou para o fato de que mudanças estão emergindo, nas práticas pedagógicas, assim como nos processos de construção de conhecimento dos estudantes, na medida em que a inclusão digital está sendo promovida pelo Programa UCA.
\end{abstract}

Palavras-chave: práticas pedagógicas; inclusão digital; Programa UCA.

Abstract: This paper aims at the analysis of teaching practices of math teachers and learning projects carried out in a public elementary school, in Panambi, a city in the state of Rio Grande do Sul (Brazil), while the school was introducing the project for laptops distributed in the "Programa UCA" (the Brazilian version of One Laptop per Child). The methodology included an interview with the school's principal and a questionnaire answered by the math teacher. The study pointed to a few changes that are emerging in the teaching practices, as well as in the students' processes of construction of knowledge as digital inclusion is being promoted by the "Programa UCA".

Keywords: teaching practices. digital inclusion. Programa UCA

\section{Introdução}

O Programa Um Computador Por Aluno - UCA é uma iniciativa do Governo Federal e do Ministério de Educação (MEC), que visa promover a inclusão digital de professores e estudantes da rede pública do ensino básico, a partir da distribuição de laptops educacionais na modalidade 1:1. O grande desafio das escolas e dos professores, em especial, é promover práticas que privilegiam a aprendizagem baseada na construção cooperativa do conhecimento, bem como na apropriação de recursos tecnológicos, visando sua utilização em práticas pedagógicas. Com base na importância que se tem dado à integração das tecnologias na educação, este estudo pretende investigar o que muda na prática pedagógica dos professores de matemática com a implantação do Programa UCA.

Atualmente, a educação escolar é compreendida diante da possibilidade de reorganização didática, pedagógica e curricular, desafiada pela facilidade do acesso às informações disponibilizadas pelas Tecnologias Digitais da Informação e Comunicação ${ }^{1}$ (TDICs), de práticas que, aliadas às TDICs, proporcionem novas maneiras de ensinar e aprender. Nesse sentido, Fagundes et al. (1999), afirmam que o currículo e o plano político

\footnotetext{
${ }^{1}$ Optamos por “Tecnologias Digitais da Informação e Comunicação” por entendermos, a exemplo de Valente (2005), Santos (2009) e Almeida (2010) que o termo não se refere apenas às possibilidades de informação e comunicação disponíveis via internet. Assim, entendemos o termo como um conjunto de aplicações tecnológicas e multimídia que podem se utilizar da internet como meio de propagação e se caracterizam por uma nova forma de materialização (bits).
}

V. $11 \mathrm{~N}^{\mathrm{o}} 1$, julho, 2013 
pedagógico precisam ser repensados, para que haja uma efetiva integração entre as TDICs e o currículo escolar. Acrescente-se que a simples presença das TDICs no ambiente escolar, por si só, não é suficiente para que ocorram mudanças na prática pedagógica. É necessária a inserção de políticas e ações que promovam uma educação digital, inserindo o uso do computador no cotidiano pedagógico da escola. É preciso que o professor crie situações relevantes com o uso das TDICs, visando uma aprendizagem mais ativa, levando em consideração a realidade dos estudantes, a fim de que se considere as TDs como instrumentos para pensar e aprender (PAPERT, 2008), e não apenas centrar as atividades no aprendizado sobre (grifo nosso) as TDICs.

Nesse contexto, o presente estudo tem como objetivo analisar as práticas pedagógicas dos professores de matemática viabilizadas por projetos de aprendizagem desenvolvidos em uma escola da rede pública de Panambi (RS) a partir da implantação do Programa UCA. Com essa finalidade, considera-se importante conhecer a realidade educacional da escola participante do Programa UCA; analisar as potencialidades pedagógicas propiciadas pelo uso das tecnologias nas aulas de Matemática; e investigar de que modo os processos de aprendizagem têm se modificado com a presença e o uso das tecnologias em sala de aula.

Inicialmente, apresenta-se um breve histórico do Programa UCA, assim como uma descrição da proposta de ensino baseada em projetos de aprendizagem. Nessa ótica, observase de que maneira o uso do computador nas aulas de matemática tem influenciado o planejamento das aulas. Ao final deste estudo, apresenta-se uma análise dos resultados baseados nos depoimentos dos professores de matemática.

\section{Breve Histórico do Programa UCA}

O Programa UCA tem sua origem na proposta conhecida como One Laptop per Child (OLPC), a qual foi apresentada por Nicholas Negroponte ao Governo Federal do Brasil, em um Fórum na cidade de Davos-Suíça, no início do ano de 2005. Em junho de 2005, os idealizadores do programa, Nicholas Negroponte, Seymour Papert e Mary Lou Jepsen vieram ao Brasil apresentar ao presidente suas ideias de forma mais detalhada. O presidente do Brasil, prontamente, aceitou a proposta e designou um grupo interministerial para avaliar e apresentar um relatório. No início de 2006, outras três instituições foram chamadas para integrar o grupo técnico para avaliar a implementação do OLPC: o Centro de Pesquisa Renato Archer (CenPRA); a Fundação Centros de Referência em Tecnologias Inovadoras (CERTI); e o Laboratório de Sistemas Integráveis Tecnológico (LSI).

Durante a primeira fase do projeto (2007) - fase pré-piloto - foram selecionadas cinco escolas, em cinco estados, como experimentos iniciais do Programa UCA, em São Paulo (SP), Porto Alegre (RS), Palmas (TO), Piraí (RJ) e Brasília (DF), visando avaliar o uso de equipamentos portáteis pelos estudantes em sala de aula. Nesta fase, três fabricantes de equipamentos doaram ao Governo Federal três modelos de laptops. A Intel doou o modelo Classmate para as escolas de Palmas/TO e Pirai/RJ. A OLPC doou o modelo $X O$ para as escolas de Porto Alegre/RS e São Paulo/SP. A empresa Indiana Encore doou o modelo Mobilis para uma escola de Brasília/DF.

Na segunda fase (2010), foram selecionadas 300 escolas públicas pertencentes às redes de ensino estaduais e municipais, mediante critérios acordados com o Conselho Nacional de Secretários Estaduais de Educação, a União Nacional dos Dirigentes Municipais de Educação, a Secretaria de Educação a Distância do Ministério da Educação e a Presidência da República.

Além da distribuição dos laptops, o MEC disponibilizou acesso à internet com conexão de banda larga, infraestrutura de rede sem fio, formação dos professores e gestores em curso específico hospedado em ambiente virtual promovido pelo e-proinfo. Para o curso, 
organizou-se uma parceria entre Instituições de Ensino Superior (IES), Coordenadorias Regionais de Educação (CREs) e Secretarias Municipais de Educação (SME), sendo esses últimos representados pelos Núcleos de Tecnologia Educacional (NTEs) e Núcleos de Tecnologia Municipal (NTMs), respectivamente. O curso ofertado pelo e-proinfo tem como metodologia a formação presencial e a distância, estruturado em módulos, que perfazem um total de 180 horas. Esses módulos abrangem as seguintes dimensões: teórica - com a finalidade de articular as teorias educacionais que possibilitam compreender os diferentes contextos de usos dos laptops; tecnológica - com vistas à apropriação e ao domínio do sistema Linux e dos aplicativos existentes nos laptops; $e$ pedagógica - visando o uso dos laptops no processo de aprendizagem.

Na fase atual, o Projeto UCA - em função do caráter piloto das duas primeiras fases passa a ser conhecido como Programa UCA. Assim, desde 2012, os computadores anteriormente doados às escolas nas duas fases experimentais - são adquiridos em processos de licitação encaminhados pelas prefeituras de cidades interessadas em distribuir os laptops na modalidade $1: 1$.

Uma vez tendo situado o Programa UCA, passa-se ao estudo realizado sobre o planejamento de projetos de aprendizagem desenvolvidos em uma escola de educação básica da rede pública, na cidade de Panambi (RS), no que tange à compreensão de possíveis avanços pedagógicos quando da inclusão digital em contexto educacional.

\section{Aprendizagem por Projetos}

A proposta de inserção dos laptops educacionais na modalidade 1:1 pode ser uma oportunidade de qualificar os professores e estimular a transformação de algumas práticas escolares centradas no professor, dando lugar a práticas centradas no estudante (VALENTINI et al, 2013). Para essas autoras, tal prática implicaria em uma aprendizagem focada na interação, na cooperação e na construção do conhecimento. A proposta de ensino baseada em projetos de aprendizagem (PAs) - abordada no Módulo $4^{2}$ do curso de formação para professores da escola UCA - parece vir ao encontro disso, visto que tem como propósito oportunizar novas e diferentes maneiras de compreender as práticas de ensino e aprendizagem. Segundo Fagundes et al (1999) e Prado (2005), a aprendizagem por projetos ou projetos de aprendizagem implica necessariamente em projetos elaborados pelos sujeitos (os estudantes) a partir de questões formuladas por eles.

Nesse sentido, o desenvolvimento de projetos de aprendizagem representa uma estratégia pedagógica inovadora, no que se refere à inserção tecnológica em contextos educacionais. Entende-se que esta estratégia pedagógica pode provocar situações em que o estudante seja o foco central do processo de aprendizagem e o professor atue como mediador ou orientador "com o objetivo de estimular e auxiliar na busca e organização de informações, o estabelecimento de relações entre as investigações, os conceitos estudados e as dúvidas e certezas dos alunos" (BONA et al, 2012. p.4). Isso exige mudanças na postura do professor que, para conduzir uma proposta de ensino contextualizado e condizente com os interesses dos estudantes, permitindo a integração de situações educacionais que possam instigar a aprendizagem, precisa também mudar suas concepções epistemológicas quanto ao processo de aprendizagem (PRADO, 2005). Em outras palavras, práticas inovadoras, centradas no estudante, conforme Coll et al (2010), apontam para a necessidade de termos professores com uma visão menos transmissiva de ensino e aprendizagem, para quem os recursos tecnológicos sejam mais do que "reforço" de conteúdos, e que tenham uma visão mais ativa ou construtivista, instigando os estudantes a utilizar esses mesmos recursos em atividades de

\footnotetext{
${ }^{2}$ Disponível em http://www.virtual.ufc.br/cursouca/modulo 4 projetos/conteudo/index.html Acesso em 04 de abril de 2013.
} 
exploração ou indagação, desenvolvendo um trabalho mais autônomo, colaborativo e cooperativo.

Nessa perspectiva, a aprendizagem por meio de projetos, enquanto abordagem metodológica, segundo Fullan (2009), é uma prática baseada na construção de conhecimento. Isso implica em uma mudança no papel do professor ao focar o processo de aprendizagem na interação com os estudantes, orientando-os a desenvolverem autonomia. Pensando no desenvolvimento de conteúdos na área da matemática, através do desenvolvimento de projetos de aprendizagem na sala de aula com a implantação do Programa UCA, entende-se que este "requer mudanças na concepção de ensino e aprendizagem e, consequentemente, na postura do professor" (PRADO, 2003, p.3).

Em relação a esse contexto, Fagundes et al (1999, p.16) acrescentam que a aprendizagem por projetos refere-se à possibilidade da construção de conhecimento pelo sujeito "em interação com o meio, com os outros sujeitos e com os objetos de conhecimento de que ele deseje apropriar-se". Ainda, segundo as autoras, na aprendizagem por projetos, "é fundamental que a questão a ser pesquisada parta da curiosidade, das dúvidas, das indagações do estudante, ou dos estudantes, e não imposta pelo professor” (p.16).

Ressalta-se que as TDICs devem ser utilizadas como recursos tecnológicos para produzir um ambiente interativo, que proporcione ao estudante práticas pedagógicas ativas centradas nas tarefas individuais ou em grupos, na solução de problemas e na construção de seu próprio conhecimento através do raciocínio lógico. A pedagogia de projetos potencializa a integração de diferentes áreas do conhecimento, bem como entre diversas mídias e recursos disponíveis na escola (PRADO, 2005).

Nesse aspecto, as orientações oficiais do Ministério da Educação (MEC), com base nos Parâmetros Curriculares Nacionais - PCNs (1997) e seus respectivos referenciais podem auxiliar na interpretação das contribuições proporcionadas pelos estudantes como parte integrante do fazer de um projeto pedagógico, propiciando a negociação de sentidos em um processo de fazer escolhas e reflexões, na tentativa de compreender tomadas de decisões e assumir responsabilidades quanto à construção de um projeto pertencente a uma comunidade escolar específica. Os Parâmetros Curriculares Nacionais (PCNs) de Matemática, por sua vez, consideram que computadores são recursos didáticos indispensáveis na atual sociedade, cada vez mais permeada por recursos tecnológicos (BRASIL, 1997).

Esse princípio de construção de projetos de aprendizagem faz com que o uso das tecnologias, quando integradas ao currículo, proporcione um ambiente inovador, onde professores e estudantes desenvolvem em conjunto seus projetos, sendo ambos, sujeitos da construção de um conhecimento matemático que lhes seja pertinente. Isso vem ao encontro do que Papert (1980) propõe, ao afirmar que educar consiste em criar situações para que os aprendizes se engajem em atividades que alimente esse processo construtivo.

Dessa forma, ao entender o conhecimento como algo que é ativamente construído pelos sujeitos de forma colaborativa e cooperativa, vale esclarecer que esses termos estão sendo considerados conforme com a perspectiva piagetiana (PIAGET, 1973). Assim, entendemos que colaborar está relacionado às ações realizadas pelos parceiros na direção de um objetivo comum, embora essas ações sejam realizadas isoladamente. Cooperar, por sua vez, “é operar em comum, isto é, ajustar por meio de novas operações (qualitativas ou métricas) de correspondência, reciprocidade ou complementaridade, as operações executadas por cada um dos parceiros.” (p.105).

Diante dessas considerações teóricas, parece-nos possível acreditar que os professores devam repensar suas práticas pedagógicas em relação à matemática, pois esta área do conhecimento, geralmente, oferece mais obstáculos à aprendizagem dos estudantes do que as demais áreas, fato observado na prática das salas de aula há décadas. Pensa-se que o distanciamento e o desinteresse dos estudantes pela disciplina de matemática possam estar 
relacionados ao fato de que, geralmente, os professores utilizam-se de estratégias de memorização e repetição como única forma de ensinar e aprender. Uma das formas de amenizar tal dificuldade poderia ser a integração das TDICs ao currículo de matemática às diversas áreas do saber e aos conhecimentos dos estudantes, ou seja, o professor poderia utilizar esse recurso a partir de uma proposta pedagógica da escola, refletindo sobre o uso desse recurso tecnológico no desenvolvimento de projetos de aprendizagem.

Tendo situado o entendimento que se tem sobre projetos de aprendizagem para o ensino de matemática mediado pela tecnologia, passa-se ao estudo realizado na escola pesquisada.

\section{Perspectiva da Gestão}

O estudo apresenta uma descrição qualitativa como forma de analisar a maneira como profissionais da matemática têm feito uso dos recursos disponibilizados pelo Programa UCA. Desta forma, adotou-se uma metodologia de pesquisa qualitativa em caráter exploratório (GIL, 1994) que concebe a utilização de questionário composto por questões abertas e fechadas. Assim, realizou-se uma entrevista com a diretora da escola, e a aplicação de um questionário aos professores de matemática.

A escola conta atualmente com 40 professores, atendendo 525 estudantes da Educação Infantil ao $9^{\circ}$ ano. Possui 12 salas de aula, laboratório de ciências, biblioteca, laboratório de informática com 15 computadores, sala de recursos, refeitório, cozinha, quadra de esportes, sala de professores, secretaria, sala da diretoria e sala para coordenação pedagógica. Como escola integrante do Programa UCA, possui um laptop por estudante e um laptop por professor.

No que se refere à implantação do Programa UCA, iniciada em 2010, a escola preparou-se para o recebimento dos recursos tecnológicos, reforçando a instalação elétrica (mais tomadas), construindo armários para armazenamento dos laptops e ampliando o sistema de monitoramento de segurança. Alguns órgãos do município de Panambi e das instituições de ensino estão engajados diretamente no Programa UCA, sendo esses: a SMEC (Secretaria Municipal de Educação e Cultura), representantes do NTE (Núcleo de Tecnologia Educacional de Ijuí), o LEC (Laboratório de Estudos Cognitivos) da UFRGS, as monitoras de informática e os professores da escola. Após a instauração oficial do Programa UCA, algumas dificuldades foram identificadas, quando da utilização dos laptops, sendo elas: banda larga de baixa potência, resultando na dificuldade de desenvolver algumas atividades online e a resistência do corpo docente quanto à inserção digital em sala de aula, embora essa já tenha sido superada. Essas dificuldades foram ressaltadas pela diretora da escola. No que diz respeito à utilização dos laptops, enquanto uso efetivo, a escola estabeleceu um cronograma visando sua utilização em caráter domiciliar, dessa forma, os estudantes podem levá-los para suas residências uma vez por mês.

Este estudo compreende que a implantação do Programa UCA e a inclusão digital causada por ele podem ser elementos desencadeadores das mudanças pedagógicas identificadas na escola. De acordo com a diretora, algumas estratégias metodológicas foram adotadas visando atividades diferenciadas elaboradas com o auxílio de aplicativos instalados nos laptops. Uma vez que os professores de diversas disciplinas da grade curricular do ensino fundamental estavam diante da inserção de tecnologias digitais, trabalhos interdisciplinares inseridos em Projetos de Aprendizagem foram elaborados em caráter experimental. A diretora da escola ressaltou que o corpo docente carece de aperfeiçoamento, no que diz respeito à ação de elaboração de projetos que sejam, de fato, interdisciplinares. Quanto ao desempenho dos estudantes, a diretora da escola acredita que estes estão mais envolvidos com as atividades temáticas propostas em sala de aula mediadas por recursos tecnológicos. 
Com o intuito de identificar projetos de aprendizagem que estão sendo desenvolvidos na escola, apresenta-se uma breve descrição de dois projetos desenvolvidos pelos professores de matemática.

O projeto intitulado Iniciação à Programação está sendo desenvolvido com o software educacional de aprendizagem Scratch no segundo semestre deste ano com estudantes do $6^{\circ}$ ao $9^{\circ}$ ano, tendo como objetivo desenvolver nos estudantes sua capacidade de criação, imaginação e o desenvolvimento do raciocínio lógico, além de introduzir o gosto pela programação sobre assuntos desenvolvidos em sala de aula.

O software Scratch é uma linguagem de programação bastante simples e intuitiva, sendo recomendado para usuários principiantes, sejam jovens ou adultos, que queiram ingressar em atividades de programação. O projeto de Iniciação à Programação desenvolvido na escola pesquisada está dividido em lições, pelas quais o professor pode ir estruturando o conteúdo que deseja ensinar, adaptando-o às necessidades cognitivas de cada série/ano. Como ação a ser desenvolvida ao término desse projeto será realizada uma Mostra de Divulgação das produções/programações na escola, prevista no planejamento geral da escola e baseada nos conteúdos e temas das respectivas séries ou anos de acordo com os Planos de Estudos da Instituição. Entende-se a realização da Mostra como uma forma de inserção e socialização de práticas vinculadas ao ensino e aprendizagem em contexto tecnológico possibilitado pelo Programa UCA.

Além do projeto mencionado, está sendo desenvolvido por uma professora de matemática o projeto intitulado Operação Matemática com UCA, com os $6^{\circ}$ anos, que tem como objetivo desenvolver a habilidade de concentração e aplicação de conhecimentos prévios para a realização das operações matemáticas no BrOfficeCalc e construção de gráficos. O projeto tem como propósito contextualizar via tecnologias, conteúdos como: operações matemáticas (adição, subtração, multiplicação, divisão, potência), construção de gráficos, tendo como fonte de dados as notas obtidas pelos estudantes em seus boletins, usadas para a realização de atividades matemáticas via software adotado. Assim como o Prof. A, a Prof. B está engajada no Programa UCA de maneira significativa, pois além de conhecer a realidade de sua comunidade escolar, participa do Plano Político Pedagógico da escola e do curso capacitação via e-proinfo para professores do Programa UCA.

A seguir, apresentam-se algumas respostas obtidas por intermédio do questionário aplicado aos professores de matemática. Ressalta-se, contudo, que a inserção tecnológica está entendida como interdisciplinar, embora este estudo esteja focado na área de matemática.

\section{Perspectivas dos Professores}

Este item apresenta excertos de narrativa dos professores entrevistados, na intenção de apontar como a ação docente vem sendo desenvolvida frente à inserção tecnológica, via Programa UCA. O questionário foi aplicado a dois professores de matemática com a finalidade de investigar os projetos de aprendizagem em andamento. A seguir, é apresentada a análise dos resultados dos questionários, com um recorte das respostas e reflexões dos professores, identificados como Prof. A e Prof. B.

O Prof. A é formado em matemática com especialização em informática, e a Prof. B em Ciência e Matemática e Matemática Pura, e não possui especialização. Sobre o tempo de atuação em sala de aula, os professores, entre 40 e 50 anos, trabalham nessa área há mais de 10 anos. Os professores responderam que já trabalhavam na escola quando o Programa UCA foi implantado e estão fazendo o curso de formação oferecido pelo e-proinfo. Esse aspecto é relevante no que diz respeito à formação e à prática docente visando que os laptops sejam utilizados de modo efetivo. Para Mercado (1999), a ferramenta por si só não opera mudanças, sendo necessário o professor passar por um processo de capacitação no uso dessas tecnologias 
em sala de aula, para saber integrar os recursos tecnológicos às práticas pedagógicas. Portanto, o curso de formação do Programa UCA parece ser de fundamental importância para o processo de inclusão digital dos professores e estudantes.

Quanto à utilização do laptop nas aulas de matemática como um recurso de apoio ao ensino, os professores responderam utilizá-lo uma vez por semana para facilitar a aprendizagem dos estudantes.

Apresenta-se abaixo trechos das narrativas dos sujeitos Prof. A e Prof. B, quanto ao que consideram eficaz para melhorar o rendimento escolar de seus estudantes.

\begin{tabular}{|l|l|}
\hline $\begin{array}{l}\text { Prof. } \\
\text { A }\end{array}$ & $\begin{array}{l}\text { "Na minha área que é a matemática, julgo ser importante para a assimilação dos conceitos e, } \\
\text { consequentemente, para a melhoria do rendimento escolar dos alunos o feedback que realizo } \\
\text { momentos atividade oxtras curriculares (casa, grupos de estudos, reforço escolar, atividades postadas em em } \\
\text { blogs...), a introdução de softwares de aprendizagens que trabalham a criação, o } \\
\text { desenvolvimento do raciocínio e a interpretação". }\end{array}$ \\
\hline $\begin{array}{l}\text { Prof. } \\
\text { B }\end{array}$ & $\begin{array}{l}\text { "Interesse, dedicação, participação em aula, realização das atividades propostas e e } \\
\text { principalmente empenho e questionamento durante a realização e os registros". }\end{array}$ \\
\hline
\end{tabular}

No que se refere ao uso do laptop nas aulas de matemática, com o objetivo de identificar se os estudantes passaram a serem protagonistas do processo de construção do conhecimento, os professores responderam que:

\begin{tabular}{|l|l|}
\hline $\begin{array}{l}\text { Prof. } \\
\text { A }\end{array}$ & $\begin{array}{l}\text { "Em parte, acredito que o computador UCA vem complementando de uma forma bastante } \\
\text { gratificante e satisfatória a compreensão daquilo que é proposto. Ele estimula, torna mais } \\
\text { atraente e dá alternativas para "construção" de conceitos que antes eram expostos de uma } \\
\text { maneira bem tradicional. Isto se observa através da utilização dos seus recursos próprios } \\
\text { (programas) e também pela busca de sites que oferecem objetos de aprendizagens. Na medida } \\
\text { em que o aluno vai interagindo com os recursos oferecidos pelo computador UCA e também } \\
\text { com os sites oferecidos e outros objetos de aprendizagens, cria-se uma estratégia diferente de } \\
\text { atingi-lo, muito mais prazerosa e também promotora da "autonomia" da busca do } \\
\text { conhecimento. Sendo assim, acredito que esta seja uma maneira de torná-lo protagonista do do } \\
\text { processo de construção do conhecimento". }\end{array}$ \\
\hline $\begin{array}{l}\text { Prof. } \\
\text { B }\end{array}$ & $\begin{array}{l}\text { "O UCA é um acessório a mais que irá auxiliar no desenvolvimento do ensino e aprendizagem, } \\
\text { sendo mais atrativo e importante". }\end{array}$ \\
\hline
\end{tabular}

Quanto ao fato do Programa UCA ter por objetivo promover a inclusão digital, foi perguntado aos professores se eles acreditam que o programa contribui para a inclusão digital dos estudantes. Os professores afirmaram que o programa contribui para a inclusão digital, dando as seguintes justificativas:

\begin{tabular}{|l|l|}
\hline $\begin{array}{l}\text { Prof. } \\
\text { A }\end{array}$ & $\begin{array}{l}\text { "Sim. Nesse sentido fica nítida a fluência que os alunos adquiriram em manipular o o } \\
\text { computador UCA e suas ferramentas em nossa escola. O Projeto UCA oportuniza a TODOS o } \\
\text { enfimón, estão atualizados e dominam as ferramentas básicas e necessárias "impostas" pelo } \\
\text { advento da informatização". }\end{array}$ \\
\hline $\begin{array}{l}\text { Prof. } \\
\text { B }\end{array}$ & $\begin{array}{l}\text { "Sim, pois permite que vários alunos tenham acesso ao computador, independente da classe, } \\
\text { religião ou situação econômica. Como a inclusão digital ele poderá realizar atividades, criar } \\
\text { programas, desenvolver a sua criatividade". }\end{array}$ \\
\hline
\end{tabular}


Por fim, os professores foram questionados quanto ao que consideram importante durante o planejamento de atividades via computador.

\begin{tabular}{|l|l|}
\hline $\begin{array}{l}\text { Prof. } \\
\text { A }\end{array}$ & $\begin{array}{l}\text { "Considero importante o retorno e o impacto que a atividade proposta irá ter sobre a } \\
\text { aprendizagem. Ao planejar a atividade, procuro levar o aluno a interpretação, a curiosidade, a } \\
\text { proximidade com a sua atual realidade e o desenvolvimento do raciocínio lógico". }\end{array}$ \\
\hline $\begin{array}{l}\text { Prof. } \\
\text { B }\end{array}$ & $\begin{array}{l}\text { "As atividades realizadas no computador serão auxiliares na aprendizagem, como maneira } \\
\text { diversificada de aprender, realizar e criar novas situações de busca para o conhecimento". }\end{array}$ \\
\hline
\end{tabular}

\section{Análise e Discussão}

Tanto o depoimento da diretora como as respostas fornecidas pelos professores ao questionário parecem indicar o comprometimento dos professores para oportunizar a interação em caráter colaborativo e o uso efetivo dos laptops, apontando para a possibilidade de o Programa UCA contribuir para o processo de aprendizagem de matemática. De acordo com os relatos, observa-se que essa aprendizagem encontra-se ainda associada, a priori, à exploração de aplicativos e softwares, etc.

Não foi possível perceber indícios de propostas de projetos de aprendizagem em sua concepção de ações centradas na curiosidade e autonomia do estudante. Os projetos estão relacionados ao conteúdo sendo desenvolvido pelos professores, os quais são responsáveis pela elaboração da proposta do projeto, contrariando o que descrevem Fagundes et al (1999) e Prado (2005) no sentido de serem os estudantes que elaboram os projetos buscando responder suas questões investigativas.

O que se pôde observar é que há um movimento em direção ao uso dos recursos tecnológicos disponibilizados pela inserção dos laptops nas salas de aula, presente, por exemplo, nos projetos Iniciação à Programação e Operação Matemática com UCA. No entanto, esses projetos não atendem aos requisitos para serem enquadrados como projetos de aprendizagem, pois sua elaboração está a cargo do professor tendo em mente o conteúdo que deseja ensinar, realizando adaptações conforme percebe as necessidades cognitivas dos estudantes. Aparentemente, de acordo com essa descrição do projeto, os estudantes não têm participação na sua elaboração e construção como investigadores ativos, conforme prevê a pedagogia de aprendizagem por projetos.

Essa percepção aponta para a necessidade de que se progrida em direção ao planejamento de projetos de aprendizagem buscando integrar conteúdos de matemática aos recursos computacionais a partir da necessidade e questionamento dos alunos (grifo nosso). Entende-se que projetos de aprendizagem em que os recursos tecnológicos sejam utilizados em um contexto investigativo, atendendo as curiosidades dos estudantes poderiam despertar uma motivação intrínseca quanto à busca de conhecimentos no campo das ciências exatas.

Na medida em que a matemática está presente no cotidiano, pensa-se que torná-la mais atraente é uma das implicações latentes aos profissionais da área.

\section{Considerações Finais}

Este estudo preliminar enfatiza como aspecto positivo a inserção tecnológica como forma de potencializar a criatividade e o raciocínio lógico no que diz respeito à aprendizagem da matemática. Os professores encontram-se envolvidos e dispostos a promover a inserção tecnológica viabilizada pelo Programa UCA, o que parece indicar a emergência - ainda que gradual - da quebra de paradigma do ensino tradicional e transmissivo. Percebe-se a preocupação em usar os laptops, com seus softwares e aplicativos, com vistas tanto a práticas 
pedagógicas que proporcionem mais autonomia por parte dos estudantes, quanto um modelo de aprendizagem mais gratificante. Por meio desta estratégia, a utilização dos laptops educacionais, em sala de aula, a autonomia dos estudantes poderá contribuir para que eles aprendam a investigar em busca da construção do conhecimento. Dessa forma, entende-se que os recursos tecnológicos poderão ultrapassar o contexto educacional da sala de aula atingindo também o âmbito social dos estudantes.

Os professores enfatizam um aspecto que parece ser primordial em relação ao Programa UCA, que é o de promover a inclusão digital dos estudantes. Por meio desta inclusão os estudantes adquiriram conhecimentos mais relacionados ao contexto instrumental, tais como: fazer downloads, criar pastas para arquivos em pendrives, dentre outras habilidades. O considerável envolvimento dos estudantes em caráter individual e coletivo, em relação às atividades propostas, aponta para um maior interesse e desenvolvimento do raciocínio lógico, observados nas atividades de sala de aula, aspectos esses ressaltados pelos professores.

Na medida em que os professores entendem o Programa UCA como desencadeador de ações de aprendizagem, pode-se inferir que a resistência docente em parte já foi superada. As ações de aprendizagem em caráter colaborativo e cooperativo permitem considerar que os aprendizes passaram a compartilhar ideias, explorando o conhecimento construído dentro e fora contexto escolar.

Quanto aos projetos vinculados ao Programa UCA e mencionados, neste estudo, acredita-se que foram identificados pontos positivos como melhor desempenho dos estudantes na disciplina de matemática; maior interesse, motivação e participação dos estudantes nas aulas, maior fixação dos conteúdos passados em sala de aula, dentre outros. Também foi possível verificar que os estudantes adquiriram algumas habilidades e competências como colaboração; socialização; criatividade; autonomia e senso crítico.

Reitera-se a observação de que os dois projetos desenvolvidos pelos professores de matemática da escola pesquisada poderiam estar mais vinculados aos reais interesses dos aprendizes, aproximando-se mais do que Fagundes et al (1999) e Prado (2005) descrevem como aprendizagem por projetos. Isso talvez se deva ao fato de que os professores estão mais focados no conteúdo programático da disciplina de matemática e não em outros elementos empíricos presentes na sala de aula, que tornariam a abordagem do conteúdo mais atraente e potencializadora do saber.

Este estudo apontou para o fato de que mudanças estão emergindo, nas práticas pedagógicas, assim como nos processos de construção do conhecimento dos estudantes, na medida em que a inclusão digital está sendo promovida pelo Programa UCA.

\section{Referências Bibliográficas}

ALMEIDA, M.E.B. Transformações no trabalho e na formação docente na educação a distância on-line. Aberto, Brasília, v. 23, n. 84, p. 67-77, nov. 2010.

BONA, A.S.de; Mattos, E.B.V.; ROSA, M.B.: PESCADOR, C.M.; FAGUNDES, L.C.; BASSO, M.V.A. Aprendizagem pela cooperação no Programa UCA: percepção dos professores a partir de Projetos de Aprendizagem CINTED/Renote. V. 10 N $^{\mathrm{o}}$ 1, julho, 2012. BRASIL. Secretaria de Educação Fundamental. Parâmetros curriculares nacionais: Matemática. Brasília: MEC/SEF, 1997. 142p.

COLL, C.; MAURI, T.; ONRUBIA, J. A incorporação das tecnologias da informação e comunicação na educação: do projeto técnico-pedagógico às práticas de uso. In: COLL, C e MONEREO, C. (org.). Psicologia da educação virtual: aprender e ensinar com as tecnologias da informação e da comunicação. Tradução Naila Freitas. Porto Alegre: Artmed, 2010. p.66-93. 
FAGUNDES, L.C., SATO, L.S., MAÇADA, D.L. Aprendizes do futuro: as inovações começaram! MEC, 1999. 96p. Disponível em: http://escola2000.net/futura/textosproinfo/livro03-Lea\%20 Fagundes\%20et\%20alii.pdf. Acesso em: 10 de novembro de 2012. FULLAN, M. O significado da mudança educacional. Porto Alegre: Artmed, 2009. 304p. GIL, A. C.. Métodos e técnicas de pesquisa social. 4 ed. São Paulo: Atlas, 1994. 207p. MERCADO, L. P. L. Formação continuada de professores e novas tecnologias. Maceió: EDUFAL, 1999. 171p.

PAPERT, S. A máquina das crianças: repensando a escola na era da informática. Tradução de Sandra Costa. Porto Alegre: Artmed, 2008. 224p.

PAPERT, S. LOGO: Computadores e Educação. Tradução ... São Paulo: Brasiliense, 1980. 253p.

PIAGET, J. . O nascimento da inteligência na criança. Tradução Álvaro Cabral. 4. Ed. Rio de Janeiro. Zahar, 1982. 387 p.

A equilibração das estruturas cognitivas: problema central do desenvolvimento. Tradução Álvaro Cabral. Rio de Janeiro: Zahar, 1975. 175p. 1973. 231p. Estudos Sociológicos. Tradução Reginaldo Di Piero. Rio de Janeiro: Forense,

PRADO, M.E.B.B. Pedagogia de projetos: fundamentos e implicações. In: ALMEIDA, M. E. B. (org.); MORAN, J. M. (org.). Integração das Tecnologias na Educação. Brasília: SEED/MEC 2005. 204 p.

SANTOS, E. Educação online para além da ead: um fenômeno da cibercultura. P.5658-5671. In: Actas do $\mathbf{X}$ Congresso Internacional Galego-Português de Psicopedagogia. Braga: Universidade do Minho, 2009.

VALENTE, J. A. Pesquisa, comunicação e aprendizagem com o computador. O papel do computador no processo ensino-aprendizagem. In: ALMEIDA, M. E. B.; MORAN, J. M. (org.). Integração das tecnologias na educação. Brasília: SEED/MEC, 2005, p. 22-31 VALENTINI C.B.; PESCADOR, C.M.; SOARES, E.M.S. O laptop educacional na escola pública: letramento digital e possibilidades de transformação das práticas pedagógicas. Educação, Santa Maria, v. 38, n. 1, p. 151-164, jan./abr. 2013. 